\title{
Comportamento plástico no escoamento de aços inoxidáveis austeníticos metaestáveis
}

\author{
Behavior plastic in yield strength of metastable austenitic stainless steel
}

Augusto Eduardo B. Antunes ${ }^{1}$, Lidia M. D. Antunes², Marcelo Sampaio ${ }^{1}$

\begin{abstract}
Resumo
Ensaios de tração uniaxiais foram empregados para deformar aços inoxidáveis dos tipos 302, 304 e 316 em diferentes temperaturas abaixo da ambiente (de $77 \mathrm{~K}$ a $300 \mathrm{~K}$ ). Na escala de microdeformação, a deformação plástica inicia-se com o deslizamento planar das discordâncias. Continuando-se com a deformação, quando diminui-se a energia da falha de empilhamento da liga e a temperatura do teste, o processo de deformação por discordâncias é substituído progressivamente por uma intensa transformação de martensita $\varepsilon$ ou maclas de deformação. Os resultados do trabalho apresentam uma referência quantitativa de alterações nas tensões de escoamento que podem ser correlacionadas a estes diferentes mecanismos de deformação.
\end{abstract}

Palavras-chave: Aço inoxidável austenítico; Ensaio de tração; Transformação martensítica; Maclagem; Tensão de escoamento; Discordâncias.

\begin{abstract}
The uni-axial tensile strength test was used for loading stainless steels of types 302, 304 and 316 at differents temperatures below room temperature (from $77 \mathrm{~K}$ to $300 \mathrm{~K}$ ). In microstrain scale, the plastic deformation starts with planar glide of dislocations. Under continuous straining, decreasing alloy stacking fault energy and test temperature, the deformation process changed progressively from a dislocation network dominant to a large $\varepsilon$ martensite transformation or twin straining band dominant microstructure. The results of work gives a quantitative picture of changes in yield strength that can be associated with these differents deformations mechanism.
\end{abstract}

Keywords: Austenitic stainless steel; Tensile test; Martensitic transformation; Twinning: Yield strength; Dislocations. 


\section{Introdução}

Durante a deformação de aços inoxidáveis austeníticos, em baixas temperaturas, além da movimentação das discordâncias na austenita, pode ocorrer simultaneamente maclas de deformação e transformações de fase do tipo austenita $=>$ martensita ${ }^{(3)}$. Estes nanomecanismos atuam como processos de deformação que competem com o deslizamento das discordâncias na rede. A ocorrência e a quantidade relativa entre eles dependem não apenas da temperatura, mas também do percentual de deformação plástica. Quanto mais baixa a temperatura de deformação e menor o teor de ligas do aço, menor a estabilidade da austenita, propiciando a formação de martensita ${ }^{(1)}$

A transformação martensítica do tipo $\gamma$ - $\alpha$ 'é espontânea para temperaturas inferiores de $M i$, entretanto, com o auxílio de energia mecânica, poderá elevar-se até a temperatura $M d$, definida como aquela acima da qual não ocorre transformação, qualquer que seja a deformação plástica. Em consequência, na faixa de temperaturas entre $M i$ e $M d$, as características mecânicas dos aços inoxidáveis austeníticos são afetadas pelas transformações martensíticas induzidas mecanicamente, que podem ocorrer de duas formas: reação martensítica induzida por tensão e reação induzida pela deformação plástica ${ }^{(15)}$. Uma caracterização simples dessas reações resulta do modo como acontece o escoamento do material. Na primeira situação, o escoamento seria devido à transformação, ocorrendo, ainda, no regime elástico e no segundo caso, o escoamento seria por deslizamento das discordâncias e, as transformações surgiriam, posteriormente, no regime plástico. A reação martensítica induzida por deformação plástica é complexa e dinamicamente associada às discordâncias, maclas e à fase martensítica intermediária $\varepsilon$, quando a estrutura austenítica apresenta baixa energia da falha de empilhamento ${ }^{(9)}$. Num aço inoxidável austenítico do tipo 304, a temperatura $M i$ seria menor que $4 \mathrm{~K}$, estando $M d$ aproximadamente na temperatura ambiente ${ }^{(11)}$.

Para avaliar os aspectos mencionados, foram efetuados em diferentes temperaturas, ensaios de tração em corpos-de-prova de três tipos de aços inoxidáveis austeníticos. Com os resultados, obtidos na forma de curvas tensão-deformação, o trabalho concentrou-se em analisar comparativamente as deformações plásticas limitadas pelo escoamento.

\section{Materiais e Métodos}

Os materiais empregados nos experimentos foram os aços inoxidáveis austeníticos dos tipos 302, 304 e 316, cujas composições químicas estão indicadas na Tabela 1.

Tabela 1. Composição química de aços austenísticos.

\begin{tabular}{|c|c|c|c|c|c|c|c|c|}
\hline Tipo & $\mathbf{C}$ & $\mathbf{S i}$ & $\mathbf{M n}$ & $\mathbf{P}$ & $\mathbf{S}$ & $\mathbf{C r}$ & $\mathbf{M o}$ & $\mathbf{N i}$ \\
\hline 302 & 0,10 & 0,54 & 0,74 & 0,032 & 0,010 & 16,7 & 0,28 & 8,3 \\
\hline 316 & 0,06 & 0,68 & 0,68 & 0,028 & 0,011 & 16,9 & 2,1 & 10,5 \\
\hline 304 & 0,08 & 0,48 & 1,78 & 0,026 & 0,010 & 18,9 & 0,46 & 8,6 \\
\hline
\end{tabular}

Para os ensaios de tração, corpos-de-prova cilíndricos foram torneados com a parte útil à deformação com $24 \mathrm{~mm}$ de comprimento e $4 \mathrm{~mm}$ de diâmetro. As demais geometrias e a fixação por rosca atendem a norma ABNT. Após a usinagem, realizou-se um tratamento térmico de recozimento a $1100^{\circ} \mathrm{C}$ por meia hora, imerso em sal, resultando uma microestrutura aproximadamente axial e com tamanho de grão da ordem de $31 \mu \mathrm{m}$ para os aços 302 e 316 e $33 \mu \mathrm{m}$ para o aço 304 . Posteriormente ao tratamento térmico, os corpos-de-prova foram polidos eletroliticamente com solução de ácido perclórico, álcool etílico e glicerina (numa relação 7:2:1), sob $1 \mathrm{~A} / \mathrm{cm}^{2}$ de densidade de corrente e potencial de $15 \mathrm{~V}$, garantindo-se assim uma superfície polida, totalmente isenta de deformação plástica, perfeitamente preparada para examinar eventuais bandas de deformação superficiais após os ensaios.

Os ensaios de tração foram efetuados com velocidade constante do travessão de carga, gerando uma taxa de deformação $\dot{\varepsilon}=4,2 \times 10^{-4} / \mathrm{s}$. Os elementos criogênicos utilizados foram nitrogênio líquido, gelo seco com acetona e gelo com água, obtendo-se respectivamente as temperaturas de $77 \mathrm{~K}, 193 \mathrm{~K}$ e $273 \mathrm{~K}$, e mais os ensaios a $300 \mathrm{~K}$.

\section{Resultados}

Entre os resultados experimentais obtidos, o trabalho restringe-se em discutir o comportamento das tensões de escoamento a $2 \times 10^{-3}$ de deformação plástica dos diferentes tipos de aço em função da temperatura, apresentadas na Fig. 1. 


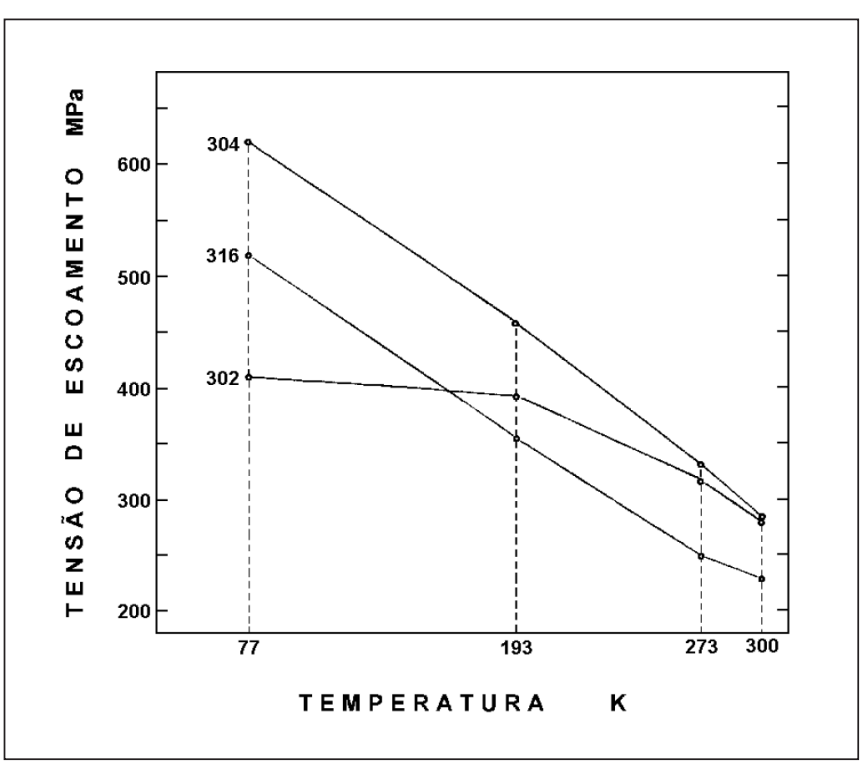

Figura 1. Influência da temperatura na tensão do escoamento dos aços.

\section{Discussão}

Um aspecto fundamental relativo aos aços inoxidáveis austeníticos metaestáveis deformados em baixa temperatura é a competitividade entre os mecanismos de deformação plástica, que se manifestam significativamente já no escoamento. Na Fig. 1, observa-se o comportamento da tensão de escoamento dos aços do tipo 302, 304 e 316 em função da temperatura. Relativo aos aços 304 e 316, verifica-se que com o decréscimo da temperatura, a partir da ambiente até $77 \mathrm{~K}$, ocorre um aumento linear da tensão de escoamento. Consequentemente, pressupõe-se a atuação de um único nanomecanismo de deformação plástica inversamente proporcional a temperatura. Neste caso, o deslizamento das discordâncias na matriz austenítica seria o mecanismo que satisfaz as condições apresentadas ${ }^{(6,17)}$.

Em todas as temperaturas de ensaio, as tensões de escoamento do aço 304 são mais elevadas que a do aço 316 , por uma parcela aproximadamente constante. Este comportamento é justificado pelo maior teor de carbono e cromo do aço 304, conforme a Tabela 1. A restrição ao deslizamento das discordâncias na rede é mais efetiva em presença de átomos intersticiais como o carbono, do que as produzidas pelos solutos substitucionais. Apesar disso, os solutos substitucionais formadores de ferrita (em ordem decrescente de atuação: $\mathrm{Cr}, \mathrm{Si}, \mathrm{Mo}, \mathrm{Nb}, \mathrm{Ti}$, etc.) também atuam significativamente, em função de seus elevados teores na composição dos aços mencionados. Elementos estabilizadores da austenita ( $\mathrm{Ni}, \mathrm{Mg}, \mathrm{Cu}, \mathrm{Co}$, etc) atuam pouco para restringir a movimentação de discordâncias ${ }^{(8)}$.

Tendo-se em mente que a tensão de deformação plástica é inversamente proporcional ao tamanho de grão da estrutura metalúrgica, segundo a relação de Hall-Petch ${ }^{(5)}$; levando-se em consideração que o tamanho de grão do aço $304(33 \mu \mathrm{m})$ é maior que os dos aços 316 e $302(31 \mu \mathrm{m})$, conclui-se que as maiores tensões de escoamento do aço 304 não se correlacionam ao tamanho de grão.

Um fenômeno significativo para a movimentação das discordâncias em aços austeníticos consiste na dissociação das discordâncias em discordâncias parciais, produzindo entre elas uma modificação na sequência de empilhamento dos planos cristalográficos, gerando localmente uma falha na sequência de empilhamento entre planos ${ }^{(11)}$ na rede $\mathrm{CFC}$, que passam a corresponder ao de uma rede HC. A região com a falha possui uma tensão superficial que tende a reunir as discordâncias parciais. A magnitude da região da falha de empilhamento depende da tensão superficial ou energia da falha de empilhamento (EFE) ${ }^{(16)}$.

As discordâncias dissociadas em parciais apresentam maiores dificuldades para ultrapassar as demais discordâncias ou "obstáculos" na rede cristalina. Neste caso, metais com discordâncias dissociadas, devido a baixa EFE, necessitam de tensões de cisalhamento crítica maiores para a movimentação das discordâncias, motivando também maiores taxas de encruamento ${ }^{(17)}$.

$\mathrm{O}$ aço 316 tem energia da falha de empilhamento da ordem de $75 \mathrm{~mJ} / \mathrm{m}^{2}$, o aço 304 da ordem de $30 \mathrm{~mJ} / \mathrm{m}^{2}$ e o aço 302 inferior a $30 \mathrm{~mJ} / \mathrm{m}^{2(14)}$. Consequentemente, as discordâncias parciais mais dissociadas no aço 304 necessitam de maiores níveis de tensões para movimentação e assim, também este aspecto contribui para justificar as maiores tensões de escoamento deste aço.

Observa-se na Fig. 1, que próximo da temperatura ambiente, as tensões de escoamento do aço 302 pouco se diferenciam das do aço 304. Este comportamento pode ser justificado, tendo em vista que o maior teor de carbono do aço 302 é compensado por um menor teor de cromo, conforme Tabela 1. Além disso, suas energias da falha de empilhamento são da mesma ordem de magnitude.

Verifica-se ainda na Fig. 1, que próximo da temperatura ambiente, as tensões de escoamento do aço 302 também aumentam linearmente com a diminuição da temperatura, de forma idêntica as dos aços 304 e 316 . Consequentemente, pode-se admitir que próximo da temperatura ambiente, os 
nanomecanismos de deformação plástica que atuam no escoamento são idênticos para os três aços. No entanto, com a diminuição da temperatura, as tensões de escoamento do aço 302 elevam-se, mas numa taxa decrescente. Portanto, com um comportamento marcantemente diferente dos outros aços. Em razão disto, em temperaturas abaixo de $193 \mathrm{~K}$, as tensões de escoamento restringem-se a um patamar de aproximadamente $400 \mathrm{MPa}$. De tal forma, que na temperatura de $77 \mathrm{~K}$, a tensão de escoamento do aço 302 tem menor intensidade que as dos aços $304 \mathrm{e}$ 316 , com diferenças respectivamente da ordem de 200 $\mathrm{MPa}$ e $100 \mathrm{MPa}$.

Em decorrência dos comportamentos mencionados, admite-se que o nanomecanismo de deformação plástica por deslizamento das discordâncias na matriz austenítica, ocorre nos aços 304 e 316 desde a temperatura ambiente até 77K. No aço 302, este nanomecanismo manifesta-se, isoladamente, somente próximo da temperatura ambiente, mas quando a temperatura diminui, surgem conjuntamente outros nanomecanismos de deformação plástica, indiretamente associados ao seu menor teor de ligas e a níveis baixos da energia da falha de empilhamento.

Uma referência quantitativa da influência dos elementos de liga sobre a estabilidade da austenita é fornecida pela expressão denominada $M d_{30}{ }^{(1)}$

$$
\begin{gathered}
M d_{30}\left({ }^{\circ} \mathrm{C}\right)=413-462(\mathrm{C}+\mathrm{Ni})-9,2 \times \mathrm{Si}- \\
8,1 \times \mathrm{Mn}-13,7 \times \mathrm{Cr}-9,5 \times \mathrm{Ni}-18,5 \times \mathrm{Mo}
\end{gathered}
$$

definida como a temperatura na qual $50 \%$ de martensita $\alpha$ ' induzida pela deformação é formada por tração após uma deformação verdadeira de 0,30 . Segundo a expressão, para os aços 302, 304 e 316, a temperatura $M d_{30}$ vale respectivamente $316 \mathrm{~K}, 281 \mathrm{~K}$ e $276 \mathrm{~K}$. Apesar deste índice se basear numa deformação verdadeira de 0,30 , portanto de muito maior magnitude que as deformações conduzidas nos experimentos do presente trabalho, a maior temperatura $M d_{30}$ do aço 302 demonstra sua maior susceptibilidade à transformação martensítica. Assim, conforme a temperatura diminui, devido a menor estabilidade da austenita, poderia ocorrer, conjuntamente com o deslizamento das discordâncias na matriz austenítica, também o nanomecanismo de deformação plástica devido as transformações martensíticas induzidas pelas deformações, até que em temperaturas da ordem de $193 \mathrm{~K}$ este mecanismo tornar-se-ia preponderante para o escoamento do aço, justificando o patamar de $400 \mathrm{MPa}$.
No entanto, até a deformação plástica de $2 \times 10^{-3}$, nos três tipos de aços examinados, a presença de martensita $\alpha$, que é ferromagnética, não foi detectada, quando os corpos-de-prova deformados foram submetidos à atração de um ímã. Em vista disso, pode-se afirmar, que até a deformação plástica do escoamento, em todas as temperaturas de ensaio, não ocorreram transformações martensíticas do tipo $\alpha$ '.

Para a análise em questão, destaca-se três aspectos significativos que coexistem antes de se atingir a deformação plástica de $2 \times 10^{-3}$. Primeiro, a densidade de discordâncias dos metais policristalinos recozidos é no mínimo da ordem de 108 por $\mathrm{cm}^{2(3)}$. Segundo, na região de microdeformação (deformação plástica de $10^{-6}$ a $10^{-4}$ ) ocorre muita movimentação e multiplicação das discordâncias, mas relativamente pouca interação entre elas ${ }^{(12)}$. O terceiro aspecto decorre da dissociação das discordâncias em discordâncias parciais, que é favorável no aço 304 e mais ainda no aço 302, devido sua menor energia da falha de empilhamento.

Em metais e ligas recozidos, com estrutura $\mathrm{CFC}$ e baixa energia da falha de empilhamento, a deformação plástica inicia-se pela movimentação das discordâncias pré-existentes confinadas aos planos mais favoráveis ao deslizamento, formam-se bandas, contendo discordâncias unitárias e discordâncias dissociadas em parciais com diferentes larguras da falha de empilhamento, dependendo da intensidade e direção das tensões locais, relativo as orientações cristalográficas do grão. Com a continuidade da deformação plástica, passa a ocorrer nas bandas a multiplicação das discordâncias, que se propagam até serem retidas por obstáculos da rede (como por exemplo, barreiras do tipo Lomer-Cottrell) ou contornos de grão. Resulta então o empilhamento das discordâncias, que atuam concentrando localmente as tensões na rede. Desta forma, podem ser atingidas as tensões críticas para nuclear maclas de deformação (Müller \& Solenthaler, 1997) ${ }^{(5)}$. Além disso, o empilhamento de discordâncias dissociadas nas bandas, ou seja, em planos paralelos próximos, sobrepõem falhas de empilhamento que geram localmente estruturas $\mathrm{HC}$ incipientes para formação de embriões de martensita $\varepsilon$. Observações com microscopia eletrônica de transmissão, tem mostrado a presença dominante de maclas de deformação e da nucleação de martensita $\varepsilon$ associada a falhas de empilhamento, quando aços inoxidáveis austeníticos são pouco deformados plasticamente em baixas temperaturas $^{(10,4)}$. Valores baixos da EFE favorecem a formação 
da martensita $\varepsilon$, que se manifesta extensivamente logo ao início da deformação plástica, associada à movimentação e multiplicação das discordâncias. Quando a EFE tem valores ligeiramente maiores, a presença de $\varepsilon$ tende a ser substituída pela macla mecânica ${ }^{(10)}$ cuja formação, portanto, exige maior intensidade de deformação plástica. Consequentemente, maiores tensões locais, motivadas pelo empilhamento das discordâncias, são necessárias para a formação de maclas do que para nucleação de $\varepsilon$.

Dependendo do tipo de aço, em função da estabilidade da austenita, também para a martensita $\varepsilon$, pode ser definida uma temperatura $E_{d}$ acima da qual as transformações $\gamma \rightarrow \varepsilon$ não podem ser induzidas pela deformação plástica ${ }^{(10)}$. Não obstante, em temperaturas maiores que $E_{d}$, a formação de maclas pode continuar ocorrendo, até que a ativação térmica torne as tensões necessárias para liberar as discordâncias de suas barreiras menor que as necessárias para a maclagem.

No aço 302, em temperaturas abaixo de $193 \mathrm{~K}$, as tensões de escoamento restringem-se ao patamar de $400 \mathrm{MPa}$, o que significa que após uma incipiente movimentação e empilhamento das discordâncias na região de microdeformação, a deformação plástica no escoamento seria preponderantemente motivada pelo surgimento da martensita $\varepsilon$ no referido nível de tensão, independente da temperatura. Acima desta temperatura, após a incipiente movimentação e empilhamento das discordâncias, a deformação plástica no escoamento torna-se preponderantemente associada à maclas de deformação. Quando a temperatura eleva-se no sentido da temperatura ambiente, gradativamente a deformação plástica no escoamento passa a decorrer da movimentação das discordâncias na estrutura austenítica de forma similar a que ocorre nos aços 304 e 316 em todas as temperaturas de ensaio.

Após os ensaios, as superfícies de todos os corpos-de-prova foram examinadas por microscopia ótica. Até a deformação de $2 \times 10^{-3}$ não foi percebida qualquer alteração superficial ou a presença de bandas de deformação. No entanto, em níveis de deformação superiores aos avaliados no presente trabalho, as bandas de deformação tem sido observadas e caracterizadamente correlacionadas aos nanomecanismos de deformação dominantes ${ }^{(2)}$.

\section{Conclusão}

Sob microdeformação (deformação plástica de $10^{-6}$ a $\left.10^{-4}\right)$, em todas as temperaturas de ensaio $(77 \mathrm{~K}, 193 \mathrm{~K}$, $273 \mathrm{~K}$ e $300 \mathrm{~K}$ ), os aços inoxidáveis austeníticos examinados (302, 304 e 316), têm como principal nanomecanismo de deformação plástica a movimentação e multiplicação das discordâncias na estrutura austenítica.

Até a deformação de escoamento (deformação plástica de $2 \times 10^{-3}$ ), em todas as temperaturas de ensaio, os aços inoxidáveis austeníticos 304 e 316, continuaram tendo como principal nanomecanismo de deformação plástica a movimentação e multiplicação de discordâncias.

Até a deformação de escoamento (deformação plástica de $2 \times 10^{-3}$ ), em temperaturas menores que $193 \mathrm{~K}$, o aço inoxidável austenítico 302, apresenta como principal nanomecanismo de deformação plástica a transformação martensítica $\gamma \rightarrow \varepsilon$, que ocorre em nível de tensão constante (da ordem de $410 \mathrm{MPa}$ ). Em temperaturas maiores que 193K, o principal nanomecanismo de deformação plástica é a maclagem mecânica. Com a elevação gradativa da temperatura de ensaio, próximo a $273 \mathrm{~K}$, o nanomecanismo de deformação plástica preponderante passa a ser a movimentação e multiplicação de discordâncias.

No escoamento (deformação plástica de $2 \times 10^{-3}$ ) do aço 302 a transformação martensítica $\gamma \rightarrow \varepsilon$ é detectada em temperaturas abaixo de 193K. Porém, admite-se que estas transformações possam ocorrer em temperaturas mais elevadas sob maior deformação plástica. Assim sendo, a temperatura $E_{d}$ seria superior a temperatura de $193 \mathrm{~K}$.

Tendo em vista a baixa energia da falha de empilhamento do aço 304, pode-se admitir também, a ocorrência de transformações $\gamma \rightarrow \varepsilon$ em baixas temperaturas (menores que 193K), além de maclas, quando as deformações plásticas forem superiores as do escoamento. 


\section{Referências}

1. Angel, T. Formation of martensite in austenitic stainless steel. J. Iron \& Steel Inst., 177, p. 165-174,1954.

2. Antunes, A.E.B. Deformação plástica em baixa temperatura de aços austeníticos metaestáveis. Observação de bandas de deformação superficiais. A ser submetido para publicação, 2009.

3. Barret, C., Massalski, T.B. Structure of Metals, Pergamon Press, 1993.

4. Brooks, J.W., Loretto, M.H., Smallman, R.E. Direct observation of martensite nuclei in stainless steel. Acta Metallurgica, v. 27, p. 1839-1847, 1979.

5. Byun, T.S. On the stress dependence of partial dislocation separation and deformation microstructure in austenitic stainless steels. Acta Materialia 51, p. 3063-3071, 2003.

6. Dieter, E.G. Mechanical Metallurgy, McGraw-Hill, 1976.

7. Hirth, J.P. Dislocations. In: PHYSICAL METALLURGY, chapter 18, Cahn, R.W. \& Haasen, P. eds, Elsevier Science Publishers, 1983.

8. Irvine, K.J., Gladman, T., Pickering, F.B. The strength of austenitic stainless steels. Journal of the Iron and Steel Institute, July, p. 1017-1028, 1969.

9. Kestenbach, H.J. Efeito da energia da falha de empilhamento sobre a deformação plástica em aço inoxidável austenítico. Metalurgia, v. 32, p. 181-186, 1976.
10. Lecroisey, F., Pineau, A. Martensitic transformation in the Fe-Ni-Cr-C system. Metall. Trans., v. 3, p. 387-396, 1972.

11. Mangonon, Jr., Thomas, G. Martensitic transformation in metastable austenitic stainless steel. Metall. Trans., v.1, p. 1587-1594, 1970.

12. Marschall, C.W., Maringer, R.E. Dimensional Instability, an Introduction. Pergamon Press, 1977.

13. Müllner, P., Solenthaler, C. On the effect of deformation twinning on defect densities. Materials Science and Engineering, A320, p. 107-115, 1997.

14. Schramm, R.E., Reed, R.P. Stacking fault energies of seven commercial austenitic stainless steels. Metall. Trans., v. 6A, p,1345-1351, 1975.

15. Scheil, E. Über die Umwandlung des Austenits in Martensit in Eisen-Nickellegierungen unter Belastung, Z. Anorg. Allgem. Chem., v. 207, p. 21-40, 1932.

16. Thomas, G., Washburn, J. Electron Microscopy and Strength of Crystals, Interscience Publishers, 1963.

17. Weertman, J., Weertman, J.r. Mechanical properties mildly temperature-dependent. In: PHYSICAL METALLURGY, chapter 19, Cahn, R.W. \& Haasen, P. eds, Elsevier Science Publishers, 1983. 